\title{
Content Comparative Investigation on Tool Wear During End Milling of AISI H13 Steel with Different Tool Path Strategies
}

\author{
Erry Yulian T. Adesta* ${ }^{* 1}$, Muhammad Riza ${ }^{2}$ Avicenna $^{3}$ \\ ${ }^{1,3}$ Department of Manufacturing and Materials Engineering, International Islamic University Malaysia, Jalan \\ Gombak 50278, Kuala Lumpur, Malaysia \\ ${ }^{2}$ Department of Mechanical Engineering, Universitas Bandar Lampung, Indonesia \\ *Corresponding author, e-mail: eadesta@iium.edu.my
}

\begin{abstract}
Tool wear prediction plays a significant role in machining industry for proper planning and control machining parameters and optimization of cutting conditions. This paper aims to investigate the effect of tool path strategies that are contour-in and zigzag tool path strategies applied on tool wear during pocket milling process. The experiments were carried out on CNC vertical machining centre by involving PVD coated carbide inserts. Cutting speed, feed rate and depth of cut were set to vary. In an experiment with three factors at three levels, Response Surface Method (RSM) design of experiment with a standard called Central Composite Design (CCD) was employed. Results obtained indicate that tool wear increases significantly at higher range of feed per tooth compared to cutting speed and depth of cut. This result of this experimental work is then proven statistically by developing empirical model. The prediction model for the response variable of tool wear for contour-in strategy developed in this research shows a good agreement with experimental work.
\end{abstract}

Keywords: high speed machining, tool wear, tool path strategy

\section{Introduction}

Tool wear prediction plays a significant role in machining industry for proper planning and control machining parameters and optimization of cutting conditions. Some researches related to tool wear has investigated during a few decades. In this paper, the recent researches in this area are reviewed.

Optimum cutting speed range is analyzed in order to minimize the tool wear when milling AISI H13. The analysis of the tool wear mechanisms show that, as the number of cutting speed range increases, on the tool flank face, oxidation wear influences more greatly, while the effect of adhesive wear decreases [1]. The most factors dominating factor effect over tool wear is cutting speed followed by feed rate and depth of cut. Abrasion was the principal wear mechanism observed at higher conditions. The feed rate is most significant parameter influences on surface roughness followed by depth of cut and cutting speed [2]. It was found that by milling of AISI H13 under different cutting speeds, as the cutting speed increases, the influences of fracture and chipping resulting from mechanical load on tool wear were reduced. At the same time the influences of adhesion, oxidation, and thermal crack accelerated by high cutting temperature became greater [3]. The tool wear under different tool path strategies that are straight-in entry and the rolling-in was investigated under milling process. It was found that the tool wear is lower for the experiment using the when roll-in strategy applied. This strategy proposes the entry of the cutter rotating on a pivot point. The cutting tool enters gradually until the nominal width of cut is reached. This technique aims to ensure the smallest chip thickness possible when exiting the cut [4]. Research on high-speed and ultra-high-speed face milling of AISI H13 steel (46-47 HRC) was conducted in order to acquire a thorough understanding of the tool wear evolution process and tool wear mechanisms in high-speed hard milling. The analysis of the tool wear mechanisms show that, as the number of cutting speed range increases, on the tool flank face, oxidation wear influences more significantly, while the effect of adhesive wear decreases [5]. 
Many researches have been carried out to investigate tool wear during machining process specifically in milling operation as mentioned previously [6-7]. However, research related to tool path application and tool wear during milling operation have not yet established. In addition to that, this research is valuable for the die and mould maker to select proper cutting condition to avoid increase in productivity and machining efficiency.

\section{Research Method}

The workpiece material used in the present works was a block of $\mathrm{H} 13$ steel which hardened and tempered to $48 \mathrm{HRc}$. The volume of the workpiece used was $130 \times 100 \times 30 \mathrm{~mm}$. Cutting tool $20 \mathrm{~mm}$ in diameter was utilized in pocketing process. The cutting tool accommodates 2 indexable inserts in every single cutting process. Coated carbide mill inserts CoroMill 490 were employed in the current study with various machining parameters including cutting speeds were 150, 200 and $250 \mathrm{~m} / \mathrm{min}$ with feed per tooth were $0.05,0.10$ and 0.15 $\mathrm{mm} /$ tooth and depths of cut involved were $0.10,0.15$ and $0.20 \mathrm{~mm}$. CoroMill 490 facilitates fouredge inserts which every cutting edge is only applied in different cutting parameter. Pocket was cut using a new cutting edge. The CoroMill 490 insert tools were securely fastened to the tool holder. The experimental works were performed on CNC vertical machining center Mazak Nexus 410A-II CNC Mill without any cutting fluid. These experiments adapted 3 different tool path strategies which are contour-in, zigzag and inclined tool path strategy as seen in Figure 1. Pocket millings were performed by varying the cutting parameters. Response Surface Method (RSM) design of experiment with a standard called Central Composite Design (CCD) was employed. There are 20 runs for every tool path strategies as output from Design of Experiment software were tested. All the process and parameters were programmed in CNC programming. When the machining process completed wear of inserts were measured by optical microscope HISOMET II.

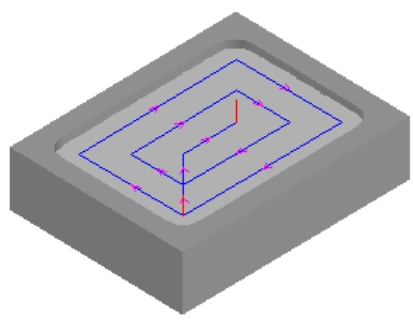

(a) Contour-in strategy

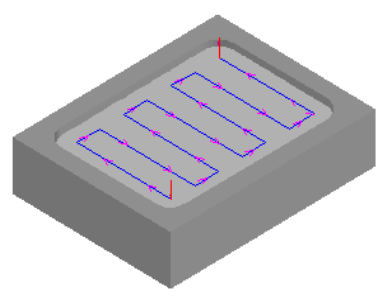

(b) zigzag strategy

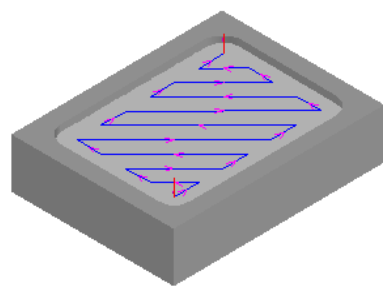

(c) inclined strategy

Figure 1. Tool path strategies applied in experiments

\section{Results and Analysis}

Experiment results reveals that the number of path segments including the finishing cut in order to make pocket for contour-in, zigzag and inclined tool paths are 11, 13 and 20, respectively. Besides that, some turning points are involved as the transition point before the cutting tool changes its direction to cut the material with different direction. The number of turning points are also different depends on the movement of tool path. The number of turning points involved in during pocketing by applying contour-in, zigzag and inclined are 9, 13 and 20 points, correspondingly. Figure 2 schematically shows the numbers of path segments, finishing cut and turning points for three tool path strategies. 


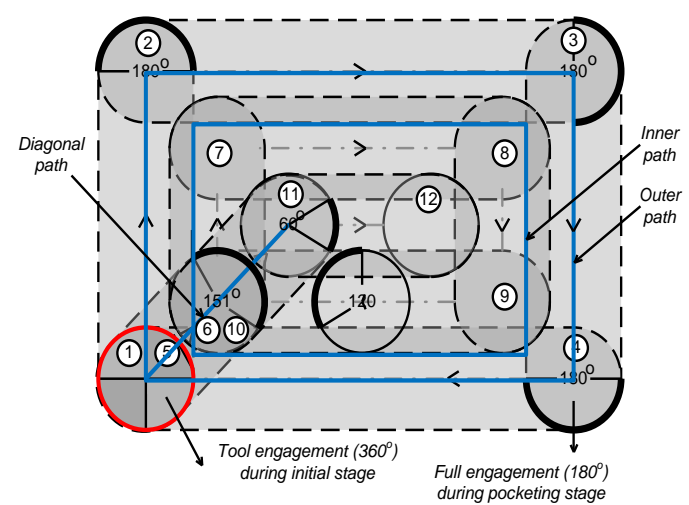

(a) Contour-in strategy

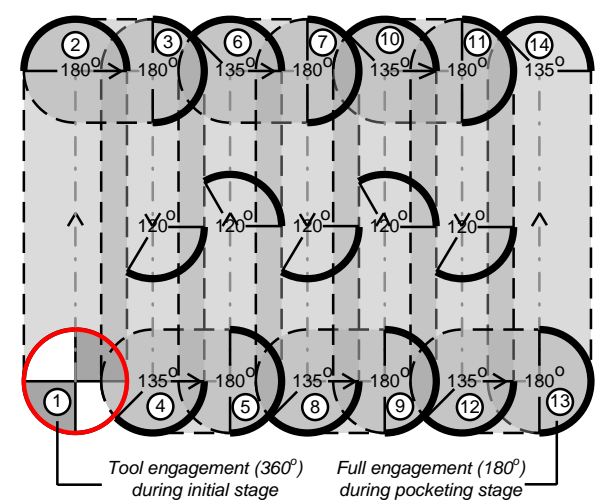

(b) Zigzag

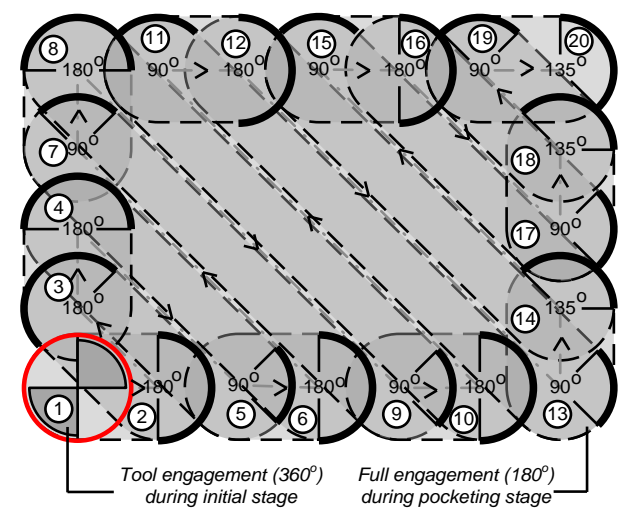

(c)

Figure 2. The number of tool path segments and turning points applied for contour-in (b) zigzag and (c) inclined tool path strategy

\subsection{Effect of Tool Path Strategies on Tool Wear}

The effect of utilizing three different tool paths strategies to tool wear development during end milling of AISI H13 is depicted in Figure 3. Contour-in is claimed as tool path strategy with the lowest tool wear development tailed by zigzag and inclined strategy. The poor tool wear caused by the number of tool engagement conditions. It is believed that the high impact forces produced when the cutting tool frequently engaged into the corner regions and turning points with combination of high cutting temperature as effect of high cutting force were the reason for poor tool wear found. The number of turning corner regions and turning points are dominant in inclined while they are medium in zigzag and small in inclined strategy as mentioned earlier in Figure 2. It should be noted that in this research, up and down milling are performed simultaneously in every segment of tool path strategy.

The results of tool wear measurements in average obtained from the research for each strategy include contour-in $0.04 \mathrm{~mm}$, zigzag $0.05 \mathrm{~mm}$ and inclined $0.08 \mathrm{~mm}$. The result is obtained from experimental work reveals that contour-in and zigzag strategy produce tool wear $49 \%$ and $31 \%$ lower than inclined strategy. The tool wear obtained are shown in Figure 4 under optical microscope (20X magnification) for three tool path strategies. 


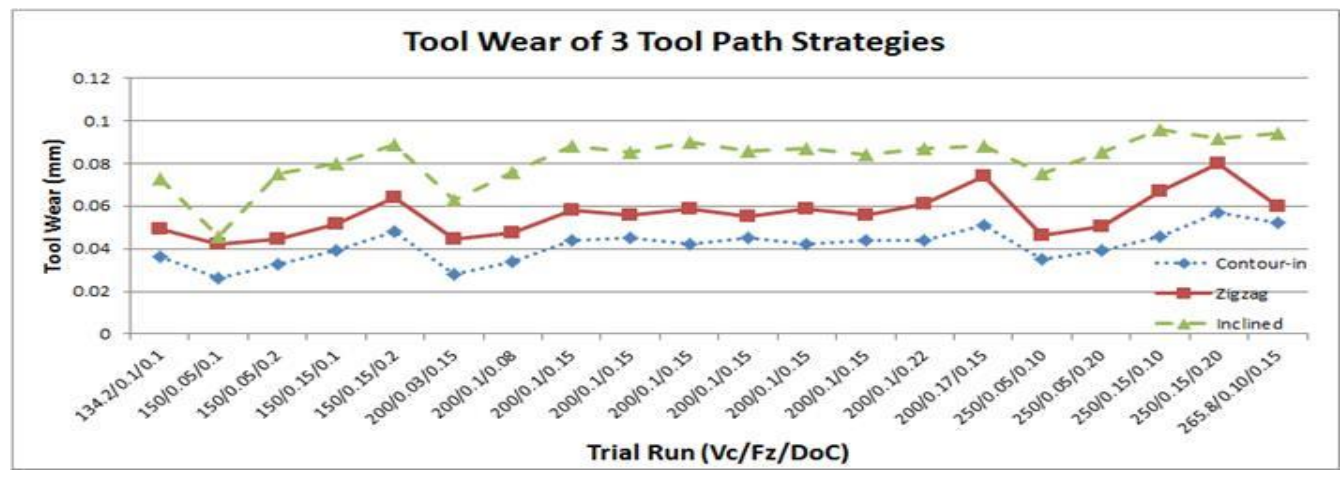

Figure 3. Comparisons of tool path strategies for tool wear

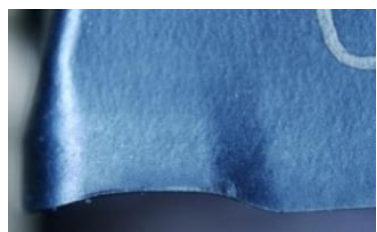

$\mathrm{VC}=150 \mathrm{~m} / \mathrm{min}$

$\mathrm{Fz}=0.05 \mathrm{~mm} /$ tooth;

$\mathrm{DoC}=0.10 \mathrm{~mm}$

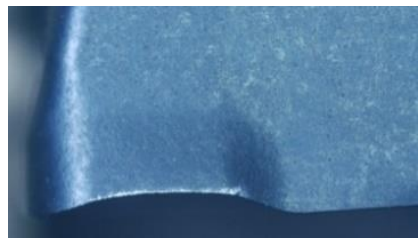

$V c=150 \mathrm{~m} / \mathrm{min}$

$F z=0.05 \mathrm{~mm} /$ tooth;

$D o C=0.10 \mathrm{~mm}$

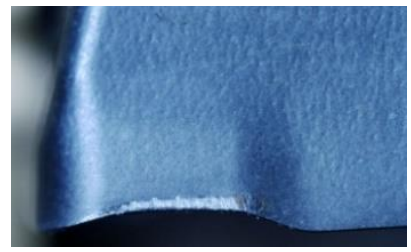

$V C=150 \mathrm{~m} / \mathrm{min}$;

$F z=0.05 \mathrm{~mm} /$ tooth;

$D o C=0.10 \mathrm{~mm}$

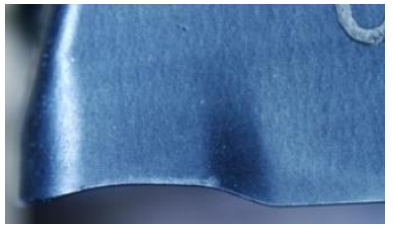

$V c=200 \mathrm{~m} / \mathrm{min}$;

$F Z=0.10 \mathrm{~mm} /$ tooth;

$D o C=0.15 \mathrm{~mm}$

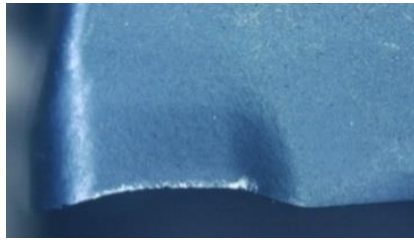

$V c=200 \mathrm{~m} / \mathrm{min}$;

$F Z=0.10 \mathrm{~mm} /$ tooth;

$D o C=0.15 \mathrm{~mm}$

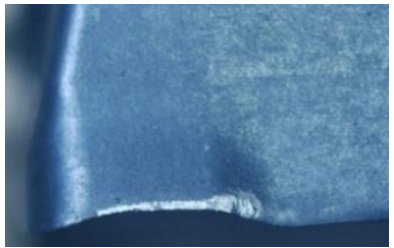

$V c=200 \mathrm{~m} / \mathrm{min}$;

$F z=0.10 \mathrm{~mm} /$ tooth;

$D o C=0.15 \mathrm{~mm}$

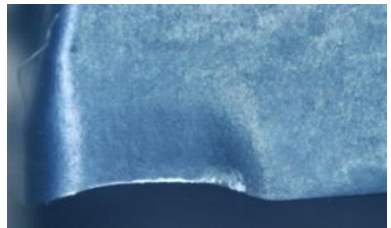

$V c=250 \mathrm{~m} / \mathrm{min}$ $F z=0.15 \mathrm{~mm} /$ tooth; $D o C=0.20 \mathrm{~mm}$

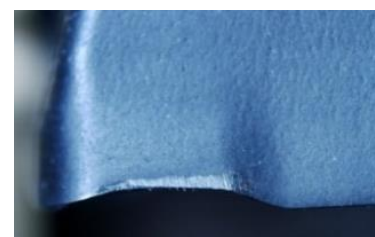

$V_{c}=250 \mathrm{~m} / \mathrm{min}$; $F Z=0.15 \mathrm{~mm} /$ tooth; $D o C=0.20 \mathrm{~mm}$

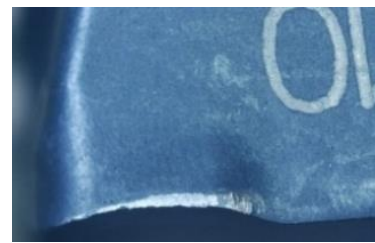

$V_{c}=250 \mathrm{~m} / \mathrm{min}$;

$F z=0.15 \mathrm{~mm} /$ tooth; $D o C=0.20 \mathrm{~mm}$

(c)

(a)

(b)

Figure 4. Tool wear development for (a) Contour-in, (b) Zigzag, (c) Inclined strategy

\subsection{Empirical Modeling of Tool Wear}

Analysis of tool wear was carried out using the analysis of variance (ANOVA) only for Contour-in strategy. This is because contour-in gives the best result among three strategies. Backward elimination procedure is selected to automatically eliminate the non-significant term to the model which resulting ANOVA table for Response Surface Reduced Quadratic Model for all strategies tested.

Table 1 shows the ANOVA model for tool wear model under contour-in strategy. The Model with F-value of 65.09 indicated that the model is significant with probability $F<0.0001$. 
There is only $0.01 \%$ a chance that the F-Model is wrong which due to noise. The values of Prob $>\mathrm{F}$ is less than 0.05 indicating the significance of model terms. In this case, two level interaction of cutting speed with feed per tooth (AB), two level interaction of cutting speed with depth of cut (AC) and second order effect of cutting speed (A2) are not the significant factor to the tool wear. Which means, main effect of cutting speed (A), main effect of feed per tooth (B), main effect of (depth of cut), two level interaction of feed per tooth with depth of cut (BC), second order effect of feed per tooth (B2) and second order effect of depth of cut (C2) are significant model terms. Apparently, the most significant effect to the tool wear is feed per tooth with F-value of 226.63.

Table 1. ANOVA Model for Tool Wear Model under Contour-in Strategy

\begin{tabular}{ccccccc}
\hline Source & $\begin{array}{c}\text { Sum of } \\
\text { Squares }\end{array}$ & df & $\begin{array}{c}\text { Mean } \\
\text { Square }\end{array}$ & $\begin{array}{c}F \\
\text { Value }\end{array}$ & $\begin{array}{c}p \text {-value } \\
\text { Prob }>F\end{array}$ & Significance \\
\hline Model & $1.145 \mathrm{E}-003$ & 6 & $1.908 \mathrm{E}-004$ & 65.09 & $<0.0001$ & significant \\
A-Cutting Speed & $2.364 \mathrm{E}-004$ & 1 & $2.364 \mathrm{E}-004$ & 80.64 & $<0.0001$ & \\
B-Feed per Tooth & $6.643 \mathrm{E}-004$ & 1 & $6.643 \mathrm{E}-004$ & 226.63 & $<0.0001$ & \\
C-Depth of Cut & $1.701 \mathrm{E}-004$ & 1 & $1.701 \mathrm{E}-004$ & 58.03 & $<0.0001$ & \\
BC & $1.012 \mathrm{E}-005$ & 1 & $1.012 \mathrm{E}-005$ & 3.45 & 0.0859 & \\
$\mathrm{~B}^{2}$ & $2.195 \mathrm{E}-005$ & 1 & $2.195 \mathrm{E}-005$ & 7.49 & 0.0170 & \\
$\mathrm{C}^{2}$ & $2.978 \mathrm{E}-005$ & 1 & $2.978 \mathrm{E}-005$ & 10.16 & 0.0071 & \\
Residual & $3.811 \mathrm{E}-005$ & 13 & $2.931 \mathrm{E}-006$ & & & \\
Lack of Fit & $2.877 \mathrm{E}-005$ & 8 & $3.597 \mathrm{E}-006$ & 1.93 & 0.2436 & not significant \\
Pure Error & $9.333 \mathrm{E}-006$ & 5 & $1.867 \mathrm{E}-006$ & & & \\
Cor Total & $1.183 \mathrm{E}-003$ & 19 & & & \\
$\mathrm{R}^{2}=0.9678$ & Adj. $\mathrm{R}^{2}=0.9529$ & Pred. $\mathrm{R}^{2=}=.9139$ & Adeq. Precision $=31.603$ \\
\hline
\end{tabular}

The model is good as the Lack of Fit is not significant with $24.36 \%$ relative to the pure error. The R2 is 0.97 which is high and close to 1 . The R2 predicted of 0.9139 is reasonable agreement with the R2adj of 0.9529 . Ratio greater than 4 for adequate precision is desirable. In this model, the value of adequate precision is 31.603 , which beyond the limit of minimum value acceptable ratio.

Figure 5 shows the normal probability plot of the studentized residuals which is used to check for normality of residuals. The plot revealed that the points on the plot lie reasonably close to the straight line which indicated that the errors are distributed normally. This support the conclusion that cutting speed (A), feed rate (B) and depth of cut $(C)$ are the significant effects and the underlying assumptions of the analysis are satisfied for all strategies employed.

Perturbation plot from Figure 6 generated by Design Expert software reveals the effect of input parameters in coded form on the output response (tool wear). It can be seen that the three input parameters, cutting speed, (A), feed rate, $(B)$ and depth of cut $(C)$ have quadratic comparable effect on tool wear. The figure also shows that at lower range of input cutting parameters (cutting speed, feed per tooth and depth of cut), the tool wear is lower compared to the higher cutting range. Feed rate affecting the tool wear less at lower range $(-1)$. However, at higher range of machining $(+1)$, feed per tooth reduces the tool wear the most. The tool wear increases significantly at higher range of feed per tooth compared to cutting speed $(A)$ and depth of cut (C). It is because when the feed rate is increased, the chip thickness is increased. Due to the combined effects of radial depth of cut (ae) and feed rate (af) resulted in the higher value of chips thickness as expressed in Equation (4.8) on page 148. As chip thickness increase, the cutting force and energy needed to remove the material from the workpiece is increased. The higher feed rate leads to the higher cutting force and cutting temperature. In turn, tool wear is occurred rapidly. At the higher cutting parameters range depth of cut affect the tool wear the least. This is because the higher depth of cut leads to the bigger contact area between cutting tool and workpiece. However, the factor of feed per tooth is higher than depth of cut in order to influence the tool wear. Such conditions are found in zigzag strategy where the feed rate affecting tool wear much more than cutting speed and depth of cut. 


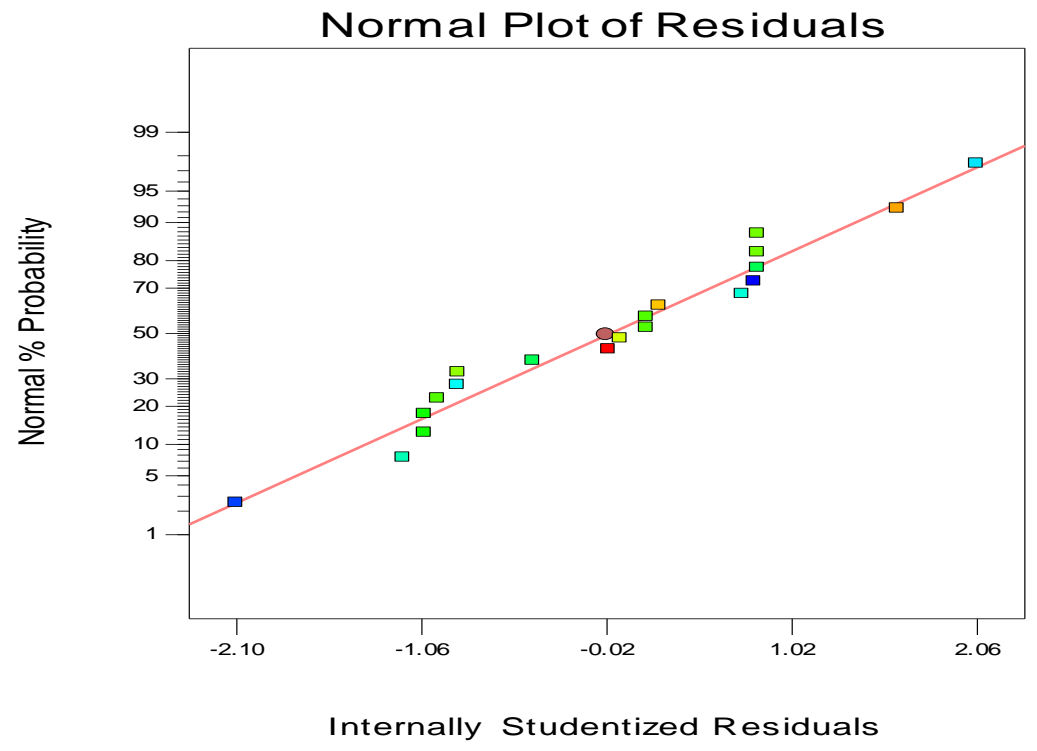

Figure 5. Normal probability of residuals for tool wear data under contour-in strategy

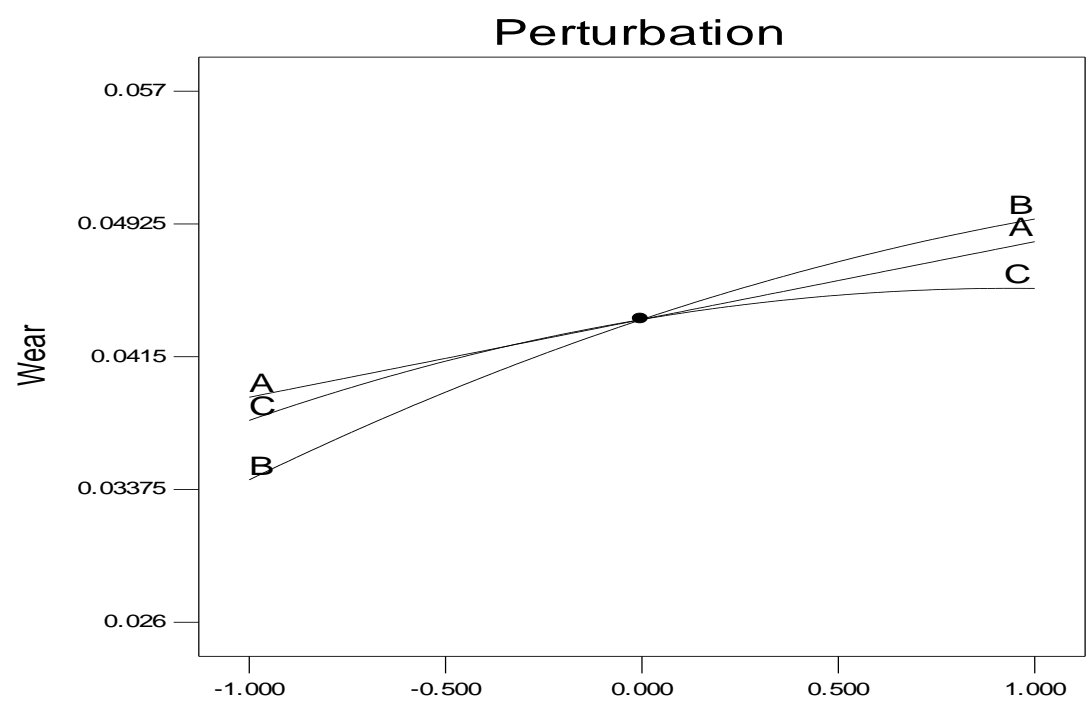

Deviation from Reference Point (Coded Units)

Figure 6. Perturbation plot of tool wear under contour-in strategy $(\mathrm{Vc}=200 \mathrm{~m} / \mathrm{min}, \mathrm{Fz}=0.10$ $\mathrm{mm} /$ tooth and $\mathrm{DoC}=0.15 \mathrm{~mm}$ )

The three dimensional graph for tool wear under contour-in strategy is shown in Figure 7. The graph has a curvilinear profile which is quadratic model fitted. It can be seen that as the cutting speed increase, the tool wear is increased. Same pattern is observed for feed rate. 


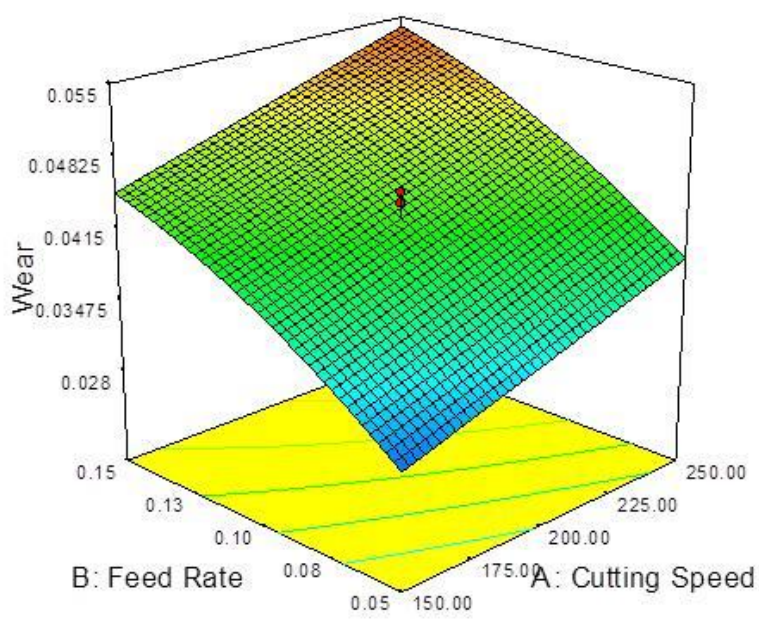

Figure 7. Contour graph of predicted tool wear under contour-in strategy

The model for the response variable of tool wear for contour-in strategy can be concluded as in Equation (1). The Equation (1) describes the quadratic surfaces as in Figure 7.

$$
\begin{aligned}
& \text { Wear } r_{\text {cont. }}=0.044+\left(4.541 \times 10^{-3}\right)^{\star} A+\left(7.612 \times 10^{-3}\right)^{\star} B+\left(3.852 \times 10^{-3}\right)^{\star} C+\left(1.125 \times 10^{-3}\right)^{\star} B^{\star} C-\left(1.752 \times 10^{-}\right. \\
& \left.{ }^{3}\right)^{\star} B^{2}-\left(2.040 \times 10^{-3}\right)^{\star} C^{2}
\end{aligned}
$$

\section{Conclusion}

Contour-in is claimed as tool path strategy with the lowest tool wear development compared to zigzag and inclined. Analysis of tool wear was carried out using the analysis of variance (ANOVA) for Contour-in strategy revealed that the most significant effect to the tool wear is feed per tooth, cutting speed and depth of cut subsequently. At lower range of input cutting parameters (cutting speed, feed per tooth and depth of cut), the tool wear is lower compared to the higher cutting range. Feed rate affecting the tool wear less at lower range. However, at higher range of machining, feed per tooth reduces the tool wear the most.

\section{References}

[1] Cui X, Zhao J, Tian X. Tool Wear in High-speed Face Milling of AISI H13 Steel. International Journal of Advanced Manufacturing Technology. 2013b; 64(9-12): 1737-1749. https://doi.org/10.1007/s00170-012-4137-9

[2] Suresh R, Basavarajappa S. Effect of Process Parameters on Tool Wear and Surface Roughness during Turning of Hardened Steel with Coated Ceramic Tool. Procedia Materials Science. 2014; 5: 1450-1459. https://doi.org/10.1016/j.mspro.2014.07.464

[3] Cui X, Zhao J, Tian X. Cutting Forces, Chip Formation, and Tool Wear in High-speed Face Milling of AISI H13 steel with CBN tools. International Journal of Advanced Manufacturing Technology. 2013a; 64(9-12): 1737-1749. https://doi.org/10.1007/s00170-012-4137-9

[4] Perez H, Diez E, Perez J, Vizan A. Analysis of Machining Strategies for Peripheral Milling. Procedia Engineering. 2013; 63: 573-581. https://doi.org/10.1016/j.proeng.2013.08.193

[5] Cui X, Zhao J, Jia C, Zhou Y. Surface Roughness and Chip Formation in High-speed Face Milling AISI H13 steel. International Journal Advance Manufacturing Technology. 2012; 61: 1-13. DOI: 10.1007/s00170-011-3684-9.

[6] Shiwei Lin. The Research and Desige of the CNC Constant Voltage Power. Indonesian Journal of Electrical Engineering and Computer Science (IJEECS). June 2014. 12(6): 4603-4608.

[7] Zhiming Feng, Guofu Yin. Variable-weight Combination Prediction of Thermal Error Modeling on CNC Machine Tools. Indonesian Journal of Electrical Engineering and Computer Science (IJEECS). September 2014. 12(9): 6797-6804. 